\title{
Prevention of diabetes-related foot ulcers and amputations: a cost-utility analysis based on Markov model simulations
}

\author{
G. Ragnarson Tennvall ${ }^{1,2}$, J. Apelqvist ${ }^{2}$ \\ ${ }^{1}$ IHE, the Swedish Institute for Health Economics, Lund, Sweden \\ ${ }^{2}$ Department of Internal Medicine, Lund University Hospital, Lund, Sweden
}

\section{Abstract}

Aims/hypothesis. We analysed the cost-effectiveness of intensified prevention in diabetic patients with different risks for foot ulcers and lower extremity amputations. Specifically, we examined whether the additional prevention costs associated with present recommendations would be offset by reduced costs of future foot ulcers and amputations.

Methods. Markov-based 5-year cost-utility simulations of current versus optimal prevention were done for hypothetical cohorts of diabetic patients older than 24 years. The model included eight possible health states for four risk groups. A population of 1677 diabetes patients provided data on present foot ulcer prevention and general mortality. Optimal prevention was defined according to the International Consensus on the Diabetic Foot. Model assumptions, transition probabilities and other data included in the model were based on published literature. The main outcome measures were cumulative incidences of foot ulcers, amputations and deaths, costs, cost-effectiveness, and quality-adjusted life years.

Results. An intensified prevention strategy including patient education, foot care and footwear is cost-effective if the risk for foot ulcers and lower extremity amputations can be reduced by $25 \%$. This is valid for all patients with diabetes except those with no specific risk factors.

Conclusion/interpretation. Providing all diabetic patients at risk or high risk for foot ulcers and amputations with adequate prevention would be a cost-effective or even cost-saving strategy. [Diabetologia (2001) 44: 2077-2087]

Keywords Prevention, markov analysis, model simulation, amputation, foot ulcer, cost, cost-effective, cost-saving, quality of life.
Interventions directed towards preventing the development or deterioration of foot ulcers in patients with diabetes mellitus have been shown to reduce the frequency of lower extremity amputations (LEA) by approximately $50 \%$ to $85 \%[1,2]$. Recently published international guidelines and con-

Received: 26 February 2001 and in revised form: 18 June 2001

Corresponding author: G. Ragnarson Tennvall, IHE, the Swedish Institute for Health Economics, Lund, Sweden. e-mail: grt@ihe.se

Abbreviations: LEA, lower extremity amputation; NBHW, National Board of Health and Welfare; PVD, peripheral vascular disease; QALY, quality adjusted life years; SEK, Swedish kronor sensus documents emphasize the importance of educating patients and health care providers, providing foot care, appropriate footwear and employing multidisciplinary foot care teams [3-6]. The need for prevention for the individual patient depends on the presence of risk factors such as peripheral neuropathy, foot deformities, peripheral vascular disease (PVD), and previous history of foot ulcer and amputation.

Despite convincing figures that foot ulcer prevention and management reduces the incidence of foot ulcers and the probability of LEA, many diabetic patients in Sweden [7,8] as well as in other countries $[3,9-12]$ do not receive optimal prevention. Possible reasons include an insufficient knowledge among health care providers and decision-makers as well as 
Table 1. Transition probabilities between health states with present prevention, age 24-69 (cycle length a half year)

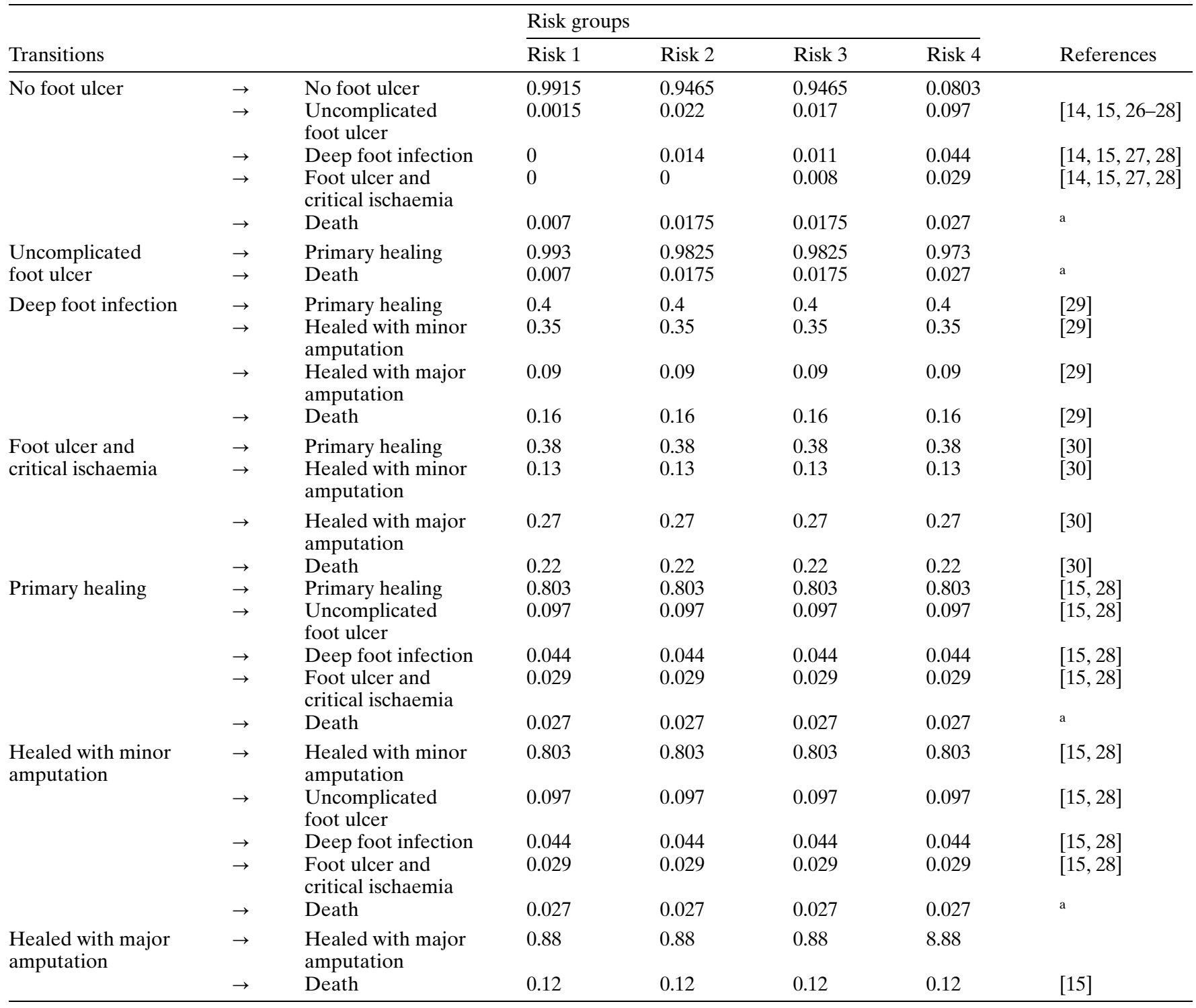

The probability of foot ulcer and amputation was assumed to be reduced by $25 \%$ with optimal prevention.

${ }^{\text {a }}$ General mortality for diabetes patients according to the reference population: age 24-69 0.007, age 70-84 0.0315, age $>85$
0.121 (Low risk, Risk 1); age 24-69 0.0175, age 70-84 0.0435, age > 850.1155 (Risk 2-3); age 24-69 0.027, age 70-84 0.0935, age $>850.113$ (High risk, Risk 4) low compliance in the patient population and economic resistance since it has not been shown that the recommended level of intervention is cost-effective. Although attempts have been made to estimate the potential cost-effectiveness of LEA prevention [13], it is difficult because the results of prevention will often not be evident until several years later, i.e. current economic resources versus future health benefits. Nevertheless, health economic studies have shown that costs due to foot ulcers and amputations are high in the short and the long run [14-16] which indicates that the potential savings from prevention can be substantial. The relation between present costs of foot specific prevention and future costs of foot complications and LEA has not been sufficiently investigated [17].

The aim of our study was to analyse for different risk categories the incremental cost-effectiveness of present international recommendations for foot ulcer prevention compared with existing prevention in patients with diabetes in Sweden. Specifically, we examined whether the additional prevention costs associated with present recommendations would be offset by reduced costs of future foot ulcers and LEA. 
Table 2. Health state unit costs, transition costs, and quality of life weights (cycle length a half year, Euro, 1998 prices)

\begin{tabular}{|c|c|c|c|c|}
\hline Health state & Baseline & $\begin{array}{l}\text { Sensitivity } \\
\text { Min }\end{array}$ & $\begin{array}{l}\text { Analyses } \\
\text { Max }\end{array}$ & References \\
\hline \multicolumn{5}{|l|}{ No foot ulcer } \\
\hline Risk 1, Low risk, present prevention & 12 & 12 & 31 & reference population \\
\hline Risk 2, present prevention & 18 & 18 & 46 & reference population \\
\hline Risk 2, optimal prevention & 124 & 100 & 299 & {$[31]$} \\
\hline Risk 3, present prevention & 25 & 25 & 62 & reference population \\
\hline Risk 4, High risk, present prevention & 35 & 35 & 114 & reference population \\
\hline Risk 4, High risk, optimal prevention & 504 & 325 & 609 & {$[31]$} \\
\hline Uncomplicated foot ulcer & 4539 & 454 & 31019 & {$[14]$} \\
\hline Deep foot infection & 15676 & 2975 & 63619 & [29] \\
\hline Foot ulcer and critical ischaemia & 8473 & 454 & 44485 & {$[14]$} \\
\hline From critical ischaemic ulcer to amputation & 47651 & 6204 & 105614 & [14] \\
\hline \multicolumn{5}{|l|}{ Quality-of-life weight (per year) } \\
\hline No foot ulcer & 0.80 & & & {$[35]$} \\
\hline Ongoing ulcer & 0.44 & & & {$[36]$} \\
\hline After primary healing of foot ulcer & 0.60 & & & {$[36]$} \\
\hline After healing with minor amputation & 0.61 & & & {$[36]$} \\
\hline After healing with major amputation & 0.31 & & & {$[36]$} \\
\hline
\end{tabular}

\section{Material and methods}

Characteristics of reference population. To provide representative patient characteristics for the study, data from a population-based survey of 1677 diabetic patients in Sweden were used [18]. The mean age was 66 years with a range from 24 to 97 years. Fifty-three per cent were men. Data from the survey have been augmented with information from physical examinations of each patient at the time of the survey (1991-1993) and medical history data from patient records. The database also includes information about present use of foot ulcer prevention in the population. With information from the database, four mutually exclusive risk groups for developing foot ulcers could be defined according to the International Consensus on the Diabetic Foot [6]. Hypothetical cohorts matching these risk groups for different age categories were simulated in a Markov model.

Five-year survival rates were available for the total reference population, and age-specific mortality could be defined for each risk group.

Definitions. Diabetic patients without any specific risk factors for developing foot ulcers are defined as having low risk (Risk 1 ), although all diabetic patients have an increased risk compared with persons without diabetes [19]. Patients with sensory neuropathy, signs of peripheral ischaemia and/or foot deformities are considered as having a risk for developing foot ulcer. Patients are divided into two groups, those with sensory neuropathy alone (Risk 2) and those with sensory neuropathy including other risk factors such as PVD and/or foot deformity (Risk 3) [6]. Patients with at least one previous foot ulcer or amputation are considered at high risk (Risk 4) [6]. According to the International Consensus on the Diabetic Foot, an optimal prevention program includes the following parts: foot inspection and examination with documentation of foot status in medical records at least once a year; access to and use of appropriate footwear; access to appropriate foot care with treatment of non-ulcerative pathology; and education of patient, family and health care providers [6]. Incidence is defined as the number of new cases during six months (one cycle) relative to the total number of persons in the population.

Markov cohort simulation. A Markov model is a useful tool when there is an ongoing risk over a long time and when important events might happen more than once [20], as in diabetic foot complications and for modelling chronic disease [21]. In the Markov model, individuals occupy one of a finite set of health states at any time [20]. Transitions between health states are expressed as transition probabilities and each health state is assigned costs for resource use and health outcome consequences associated with the state. By running the model over a number of cycles, the long term costs and outcomes associated with a disease and with interventions can be estimated [20].

The present Markov model contained eight possible health states including no ulcer, three foot ulcer states, three outcome states and death (Fig. 1). Each baseline analysis was based on a 5 -year model with a cycle length of half a year, i.e. ten cycles. The cycle length was determined from previously reported wound healing times between three to seven months [22]. Transition probabilities, costs and quality of life adjustments associated with each health state in the four risk groups were determined with information from published reports (Tables $1,2)$. The main outcome measures analysed in the model were: cumulative incidences of foot ulcers, amputations and deaths after five years of prevention, expected five-year costs after present versus optimal prevention, incremental cost-effectiveness of optimal prevention and quality adjusted life years (QALYs).

Markov model simulations were carried out for four cohorts: Risk 1(low risk, no specific risk factors); Risk 2 (only 


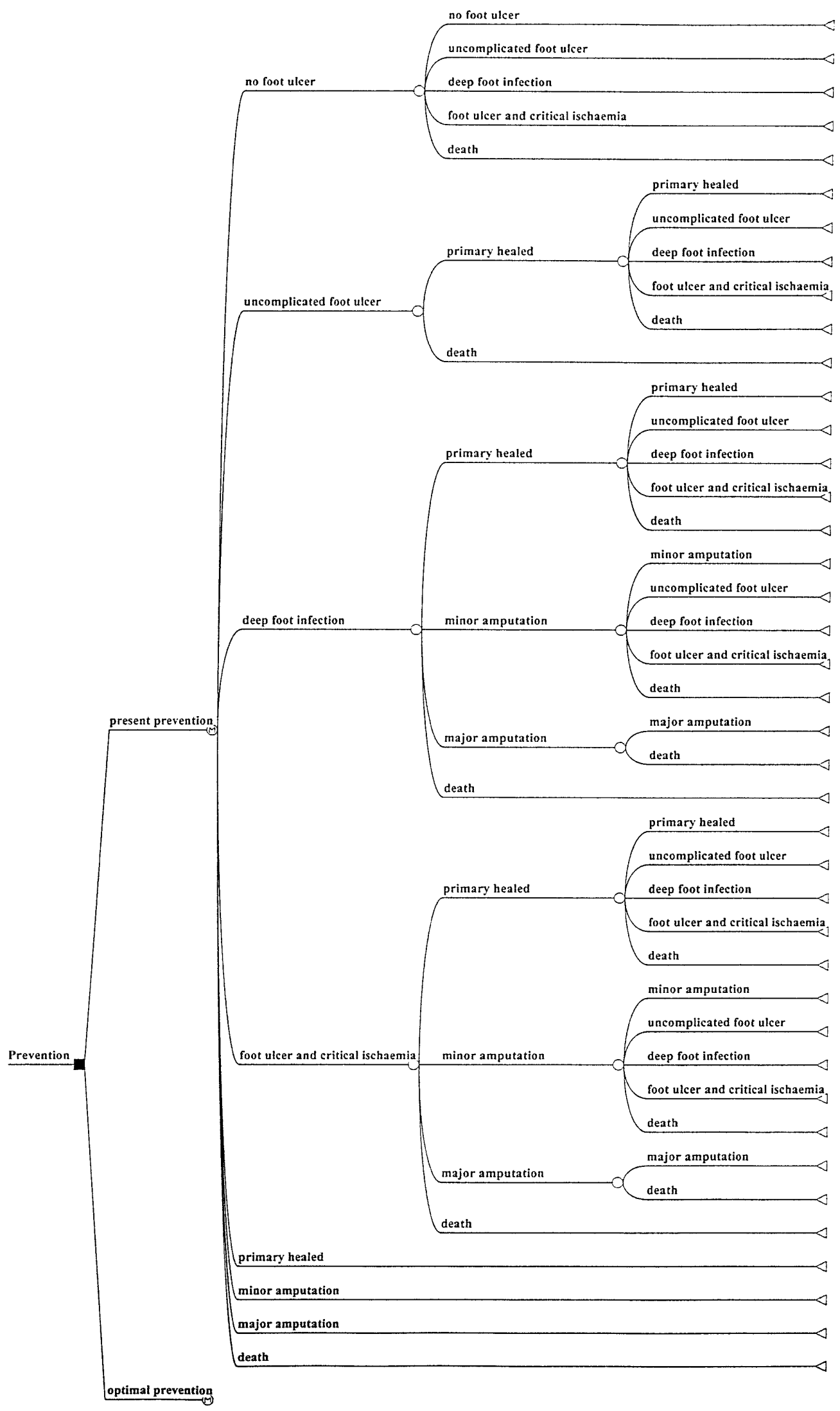

Fig.1. Markov model. The tree structure is identical for present and optimal prevention 
neuropathy); Risk 3 (neuropathy and PVD and/or foot deformity); and Risk 4 (high risk, previous foot ulcer or amputation). The distribution of patients in the reference population was $42.3 \%$ low risk, $15.1 \%$ Risk 2, $28.0 \%$ Risk 3 and $14.6 \%$ high risk patients.

Each model simulation represented a hypothetical cohort of 10000 Swedish diabetic patients 24 years of age or older. In the simulations the present level of prevention in each risk group in the reference population was compared with an intervention strategy defined as optimal patient prevention according to present guidelines for each risk cohort. Separate simulations with different mortality rates were done for three age groups in every risk category: 24 to 69 years, 70 to 84 years and 85 years and older. In total, baseline analyses were done for 12 different cohorts.

Foot ulcers and amputations. Because the majority of LEA in diabetic patients are preceded by a foot ulceration [1], the model was simplified with the assumption that all LEA are precipitated by foot ulcers. Foot ulcer health states were defined according to maximal type of ulcer during a cycle, i.e. the most severe type of a foot ulcer during an ulcer episode. Present and optimal prevention were assumed to start in the first cycle according to risk group. Both present and optimal prevention continued in all ulcer-free cycles during the simulation period of five years (ten cycles). A low risk (Risk 1) or risk patient (Risk groups 2 and 3 ) in the no ulcer state had no history of foot ulcer. After healing from a first ulcer, the low risk and risk patients had the same probability for a new foot ulcer as a high risk patient (Table 1). Prevention was then assumed to be the same as for the high risk patients.

The probability of experiencing more than one foot ulcer per year was assumed to be zero, i. e. patients have to continue to an outcome state before entering a new foot ulcer state. Patients in the major amputation health state could only remain in that state or continue to the dead state. Patients in the minor amputation state face a continued risk of transitioning to another foot ulcer state in case of a new ulcer, but not directly to the major amputation health state. The probability that patients with minor amputations develop a new ulcer was the same as the risk for high-risk patients with no history of amputation. The probability of staying in the minor amputation state was the same as having no ulcer in the high risk group. In the baseline analysis optimal foot ulcer prevention was assumed to reduce the incidence of both foot ulcers and amputations by $25 \%$ [23-25]. Alternative reductions of foot ulcer and LEA incidences were introduced in sensitivity analyses. The pathway between health states in the model was identical for present and optimal prevention, but with different probabilities for the incidence of foot ulcers and amputations as described above (Fig. 1).

Epidemiology morbidity. The annual incidence of foot ulcers in the low risk group was assumed to be $0.3 \%$, i. e. the same incidence as for leg ulcers in an unselected Swedish population [26]. Patients at low risk (Risk 1) were assumed to be only at risk for uncomplicated or superficial ulcers. The annual incidence of foot ulcers in patients with neuropathy only (Risk2) was $7.2 \%$ [27], a value assumed for patients with neuropathy and other risk factors such as PVD and foot deformity (Risk 3). Patients with neuropathy (Risk 2) were assumed to be at risk only for uncomplicated ulcers or deep foot infections, whereas patients with neuropathy and other risk factors (Risk 3 ) could have foot ulcers with critical ischaemia as well (Table 1). For patients at high risk (Risk 4) for foot ulcers the yearly incidence was assumed to be $34 \%$ or the same as the risk for developing a recurrent ulcer during the first year after healing of a previous foot ulcer [28]. The distribution of ulcer types in the risk and high risk groups was obtained from previous studies $[14,15]$ (Table 1). These figures were then multiplied with the incidence rates $-7.2 \%$ for Risk 2 and Risk 3 patients and $34 \%$ for high risk (Risk 4) patients - to obtain yearly probabilities for each type of ulcer in the risk groups. Probabilities per cycle were obtained by the formula $1-\sqrt{ } 1-p_{\text {year }}$ (Table 1 ) [21]. As the probabilities of moving to states in each cycle must sum up to 1 , the probability of staying in a state without ongoing ulcer was simply 1 minus the sum of the probabilities of leaving the state (Table 1).

Outcome probabilities for patients with foot ulcers were differentiated according to type of ulcer $[14,29,30]$ (Table 1).

Epidemiology mortality. The probability of death was differentiated by type of ulcer [29, 30] (Table 1). Patients with uncomplicated ulcers were assumed to have the same age-specific probabilities of dying as persons with diabetes in general. The probability of non-complication-specific mortality for a diabetic population was based on NBHW data of actual five-year mortality in the reference population. To obtain an annual transition probability of mortality, the following formula was used: $\mathrm{tp}_{1}=1-\left(1-\mathrm{tp}_{5}\right)^{1 / 5}$ where $t \mathrm{p}_{1}$ is the yearly transition probability and $t p_{5}$ is the five-year probability of mortality [21]. The probability of mortality after major amputation was taken from a previous study [15].

Interventions. In the reference population, $20 \%$ of low risk (Risk 1) patients, $30 \%$ of patients at risk (Risk 2, neuropathy only), $39 \%$ of patients at risk with neuropathy, PVD and foot deformity (Risk 3 ) and $43 \%$ of patients at high risk (Risk 4) used any type of chiropodist service. In the corresponding risk groups, $5 \%, 8 \%, 16 \%$ and $34 \%$, respectively used protective or therapeutic footwear and these proportions were used in both the baseline and the sensitivity analyses of current prevention. Annual resource use in the baseline analysis of current prevention was assumed to be two visits to a chiropodist and one pair of special insoles in all risk groups. Resource use was varied, however in the sensitivity analysis. The minimum level of resource use was assumed to be the same as at baseline, whereas the maximum number of annual chiropodist visits was assumed to be six in all risk groups. The maximum level of protective or therapeutic footwear was assumed to be the same as in the baseline analysis of current prevention in all risk groups except the high risk group. For the $34 \%$ of patients assumed to receive this type of prevention one pair of shoes per year was allocated (Table 2).

In the baseline analysis, optimal prevention was calculated according to present international recommendations [6] and the following use of resources modified from the Swedish consensus conference [31]: All diabetic patients receive education about foot care. All patients at risk (Risk 2, neuropathy only) receive professional foot care from a chiropodist three times annually. All patients at risk with neuropathy, PVD and/or foot deformity (Risk 3 ) receive foot care six times a year and $50 \%$ are provided with one pair of shoes and $50 \%$ receive special insoles every year. All patients at high risk (Risk 4) receive foot care six times a year and two pairs of protective or therapeutic shoes every year. In the baseline analysis of optimal prevention, patients in the low risk group were assumed to include the same level of professional foot care and special footwear as in present prevention, implying a somewhat higher level of optimal prevention requirements than presently recommended (Table 2).

For low-risk patients, the minimum level of optimal prevention included patient education only and the maximum level was assumed to be the same as in the baseline. For patients 
Table 3. Markov model cohort simulations, baseline results ( $25 \%$ incidence reduction of foot ulcers and LEA after optimal prevention). Total expected five-year costs and QALYs per patient for prevention and treatment of foot ulcers and amputations (Euro, 1998 prices, discount rate 3\%)

\begin{tabular}{|c|c|c|c|c|c|c|c|c|c|c|c|c|}
\hline & \multicolumn{4}{|c|}{$\begin{array}{l}\text { Age 24-69 } \\
\text { Risk group }\end{array}$} & \multicolumn{4}{|c|}{$\begin{array}{l}\text { Age } 70-84 \\
\text { Risk group }\end{array}$} & \multicolumn{4}{|c|}{$\begin{array}{l}\text { Age }>85 \\
\text { Risk group }\end{array}$} \\
\hline & 1 & 2 & 3 & 4 & 1 & 2 & 3 & 4 & 1 & 2 & 3 & 4 \\
\hline Costs, present prevention & 185 & 4169 & 5561 & 13872 & 164 & 3708 & 4966 & 11127 & 108 & 2841 & 3840 & 10464 \\
\hline Costs, optimal prevention & 591 & 3930 & 5823 & 13072 & 520 & 3471 & 5148 & 10185 & 330 & 2605 & 3836 & 9495 \\
\hline Difference in cost & 406 & -239 & 262 & -800 & 356 & -237 & 182 & -942 & 222 & -236 & -4 & -969 \\
\hline QALYs, present prevention & 3.24 & 2.89 & 2.87 & 2.04 & 2.84 & 2.51 & 2.50 & 1.53 & 1.78 & 1.76 & 1.75 & 1.40 \\
\hline QALYs, optimal prevention & 3.24 & 2.93 & 2.92 & 2.08 & 2.85 & 2.56 & 2.54 & 1.54 & 1.78 & 1.78 & 1.77 & 1.41 \\
\hline Difference in QALYs & 0 & 0.04 & 0.05 & 0.04 & 0.01 & 0.05 & 0.04 & 0.01 & 0 & 0.02 & 0.02 & 0.01 \\
\hline Incremental cost/QALY & not c-e & dom & 5087 & dom & not c-e & dom & 4045 & dom & not c-e & dom & dom & dom \\
\hline
\end{tabular}

not c-e: not cost-effective ( $>100000 /$ QALY in all age groups in risk group 1), the optimal prevention alternative yields higher costs, but not a sufficient increase in quality of life to allow

in Risk group 2, a minimum of two and a maximum of six chiropodist visits were included. Special footwear was assumed for patients in the maximum alternative with $50 \%$ receiving shoes and $50 \%$ receiving special insoles. In Risk group 3, the minimum level of optimal prevention was assumed to be the same as in the baseline analysis. The maximum level of prevention was assumed to include 12 visits and either two pairs of protective or therapeutic footwear $(50 \%)$ or two pairs of special insoles $(50 \%)$. In the high risk (Risk 4 ) group 6 annual chiropodist visits, two pairs of shoes for one third of the patients, and special insoles for the remaining two thirds were assumed for the lowest level of prevention. The maximum prevention for this group was assumed to include 12 chiropodist visits and two pairs of protective or therapeutic shoes. Patient education was assigned to all risk groups in both minimum and maximum optimal prevention.

The level of prevention within each risk group reflects an average use of resources according to the descriptions above. The consumption of foot care and footwear could differ between patients within the same group. For example one patient can be provided with semi-orthopaedic shoes while it is sufficient for another patient to have athletic shoes of good quality.

Costs. Costs of present and optimal prevention were assigned to health states without ongoing foot ulcer treatment, i.e. no ulcer, primary healed and healed with minor amputation. In the minor amputation health state, both costs to prevent new foot ulcers and amputations as well as costs associated with the need for increased home care and social service due to the amputation were included [15]. Costs applied to the state healed with major amputation, represented the additional costs of staying in that state during one cycle due to an amputation above the ankle. These costs included home care and social service, prostheses, inpatient and outpatient care associated with the major amputation health condition but also costs related to an increased risk for new foot ulcers and amputations during the cycle [15].

For patients undergoing amputation, a cost for transition from an ulcer state to an amputation state was calculated as the difference between costs for healing with and without amputation for a specific type of ulcer, respectively (Table 2). Unit costs of foot ulcer treatment and amputations were collected from published reports [14, 15, 29].

Costs were inflated to 1998 SEK (Swedish kronor) and then converted to Euro (average exchange rates in 1998: $£ 1$ sterling $\approx 13.17$; \$ US1 $\approx 7.95$; Euro $1 \approx 8.93$ ). A discount rate of $3 \%$ reasonable cost-effectiveness rates ; dom: dominating, the optimal prevention alternative yields both lower costs and higher QALYs (cost-saving)

was used in the baseline analyses and 5\% in the sensitivity analyses to convert future costs and health effects into present value $[32,33]$. Additional sensitivity analyses were done where both costs and health effects were not discounted. Unit costs from previous years were adjusted for inflation to 1998 prices with an index from the Federation of County Councils [34]. Half-cycle corrections for both costs and health effects were applied in the model [20]. All relevant direct costs were considered independent of where they occurred but the indirect costs of lost production due to short-term illness were not included.

Quality of life. Quality of life assessments for the eight possible health states based on the generic EuroQol instrument were obtained from a previous study and the literature $[35,36]$ (Table 2).

Other health economic assessments. One-way sensitivity analyses and Tornado diagrams were carried out to determine the accuracy of the baseline model simulations and the extent to which the different parameters and choice of parameter values have influenced results. In the Tornado diagrams, all unit costs for prevention and treatment of foot ulcers and amputations were varied simultaneously including a lowest and a highest value as described in Table 2 . For each variable a range of possible outcomes generated by varying the related variable were produced. In addition, the robustness and validity of the simulation model were checked by comparing the cumulative outcome results with previously published national estimates of foot ulcers and amputations [31, 37].

The model simulations were done with the software DATA3.0, TreeAge Software (Williamstown, Mass., USA) and the study was approved by the local ethics committee and carried out according to the Swedish law for handling of information containing personal data (Personal Data Act, SFS 1998: 204).

\section{Results}

Baseline results. For high risk patients, an optimal prevention including patient education, use of appropriate footwear and access to foot care is cost-saving under the baseline assumption of $25 \%$ lower incidence of both foot ulcers and LEA (Table 3). 
Table 4. Cumulative outcome distribution of baseline cohort simulations ( $25 \%$ incidence reduction of foot ulcers and LEA after optimal prevention). Patients in each health state after five years with present or optimal prevention (cohorts $n=10000)$

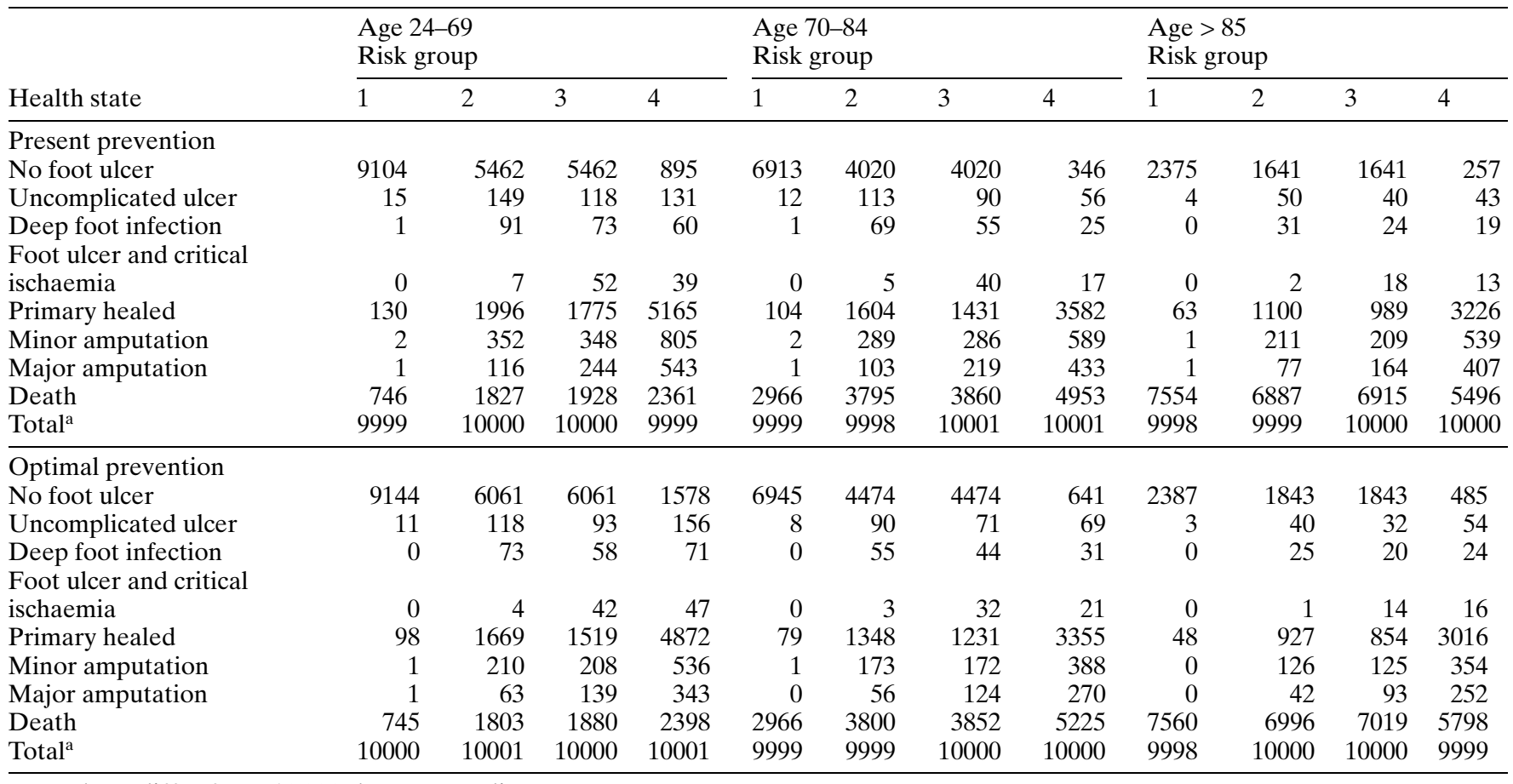

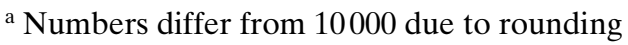

Under the same set of assumptions, optimal prevention in the low risk group increased costs by approximately Euro 220 to Euro 400 per patient during five years but with modest improvements in outcome and without any improvements in quality adjusted life years (QALYs) (Table 3).

In patients with sensory neuropathy only (Risk 2), decreased costs of about Euro 240 per patient were found for the same period. For patients with neuropathy and other risk factors (Risk 3) optimal prevention was associated with additional costs of approximately Euro 180 to Euro 260 in the two youngest cohorts and decreased costs of about Euro 4 in patients older than 85 years. The improvements in QALYs were modest in all cases (Table 3 ).

During the time frame of the analysis, approximately 70 to 150 of the patients at low risk in different age groups in cohorts of 10000 and still alive after five years had developed a foot ulcer with present prevention requirements (Table 4). Among patients in the Risk 2 and Risk 3 cohorts the corresponding number of patients who had developed foot ulcers was between 1400 and 2900 (Table 4). In the high risk group, between 4250 and 6750 of patients surviving five years had developed a foot ulcer (Table 4). Moreover, an additional number of patients who were deceased at 5 years had developed foot ulcers before they died. In total, 109 to 173 ulcers in low risk patients, 2297 to 3551 in Risk group 2, 2270 to 3503 in Risk group 3, and 6745 to 9121 foot ulcers in high risk pa- tients were registered by the simulation model with present prevention (Data not shown). Extrapolated to the total Swedish population of patients with diabetes who were 24 years and older (approximately 300000 ) according to the risk distribution in the reference population, the number of foot ulcers over five years would be 60396 to 87651 , which translates to approximately 12100 to 17500 per year. This estimated total number of new foot ulcers per year based on the model simulations correspond with the previously estimated number of foot ulcers in Sweden [31].

The number of patients in cohorts of 10000 who had undergone amputations with present prevention and who were still alive after five years were 2 to 3 in patients with initial low risk, 288 to 468 in Risk group 2373 to 592 in Risk group 3, and 946 to 1348 in the high risk group. If these amputation rates were extrapolated to the Swedish diabetic population in the same way as foot ulcer rates the total number of LEA would be approximately 1500 to 1600 per year which is almost the same as previously published figures [37].

The accumulated total number of deaths in the model with present prevention corresponded with the expected number from the reference population.

Sensitivity analysis. Varying the discount rate only had no major influence on the results (Table 5). Assuming about a $25 \%$ lower foot ulcer incidence but without any further reduction in LEA than generated 
Table 5. One-way sensitivity analysis. Incremental cost/QALY for prevention and treatment of foot ulcers and amputations (Euro, 1998 prices)

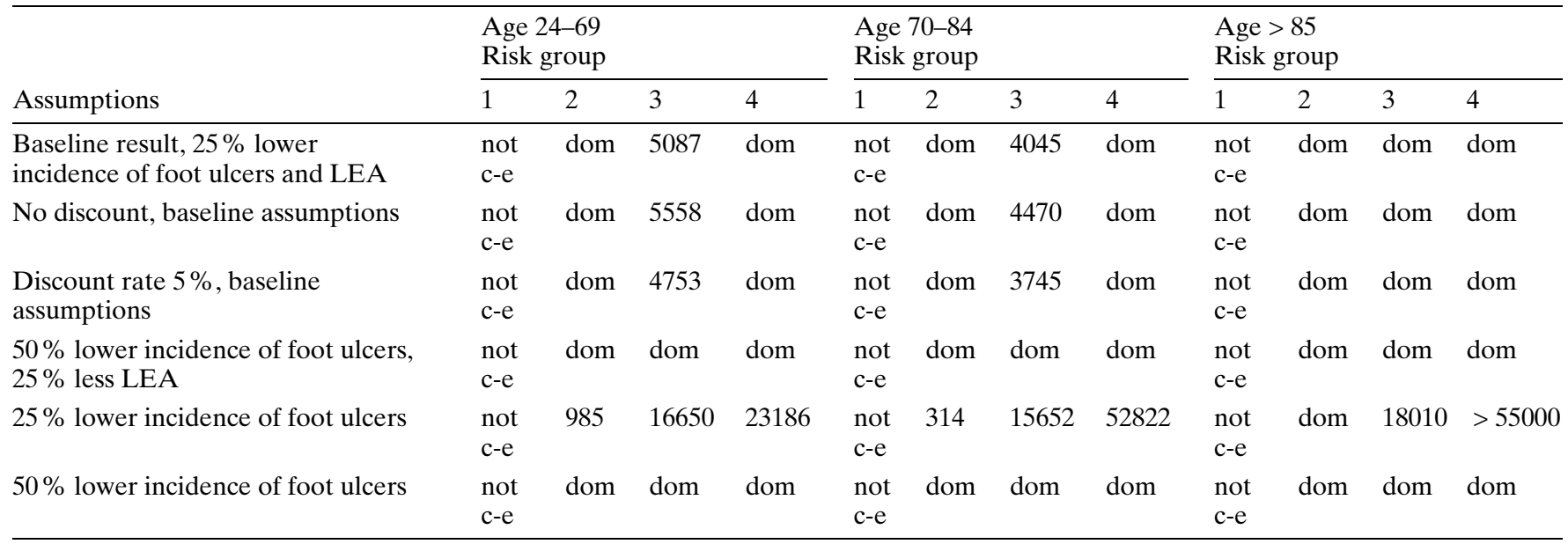

not c-e: not cost-effective ( $>100000 / \mathrm{QALY}$ in all cases in risk group 1), the optimal prevention alternative yields higher costs, but not a sufficient increase in quality of life to allow rea- sonable cost-effectiveness rates; dom: dominating, the optimal prevention alternative yields both lower costs and higher QALYs (cost-saving) by less foot ulcer incidence would imply that the two oldest cohorts in high risk patients could not be considered cost-effective with optimal prevention in comparison with present prevention (Table 5). All other cost-effectiveness ratios generated by the model simulations are in the same range as other medical treatments that have been widely adopted in Sweden. Cost-utility ratios less than US \$ 25471 and US \$ 52346, about Euro 22600 to 46600, (1998) have been identified as very attractive in sources from the United States and Canada [17].

Further in the sensitivity analysis, reductions of $50 \%$ in the development of foot ulcers with and without the previously assumed $25 \%$ reduction of LEA in the main analysis were examined in one-way analyses. With both alternatives, an optimal prevention would be cost-saving in all risk groups except the low risk group. In this group both ulcer reduction alternatives would imply a somewhat higher cost but without further health improvements (Table 5).

Using a lower risk of foot ulcers for patients with neuropathy (Risk 2), $4.95 \%$ [38] instead of $7.2 \%$ as in the baseline analysis changes the main results for patients 85 years and older. For this group an optimal prevention would cost Euro 2591/QALY, which is considered cost-effective, whereas in the two youngest cohorts an optimal prevention would still be cost saving.

The baseline effect of a $25 \%$ lower risk of both foot ulcers and LEA on variations of all present and optimal prevention costs was depicted in Tornado diagrams according to the specified minimum and maximum. This altered the results in six cohorts. Specifically, an optimal prevention strategy would be costeffective, but not cost saving in patients with sensory neuropathy (Risk 2) in the three age groups if the prevention costs per cycle exceeded Euro 170, Euro 175 and Euro 191, respectively instead of Euro 124 as in the baseline case. This implies, for example, that an intensified prevention is still cost-saving if patients in the three age groups have four to five chiropodist visits annually instead of three, provided they receive the same level of education and footwear as in the baseline cases. An optimal prevention would not be cost-saving in Risk 3 patients older than 85 years if the prevention cost per cycle exceeded Euro 307 instead of Euro 293. The results would, however, be cost-effective as in the other two age groups in Risk 3 patients.

An optimal prevention was not cost-saving in the baseline analyses for Risk 3 patients in the two youngest cohorts, but resulted in rather favourable cost-effectiveness ratios of Euro 4045 and Euro 5097. The Tornado diagrams showed that also the results for these two groups would be cost-saving if the cost of present prevention was slightly higher, Euro 50 and Euro 42 instead of Euro 25 per cycle as in the baseline analysis. The baseline results were not sensitive to any other variation between the minimum and maximum levels of prevention.

\section{Discussion}

No economic analysis of foot care interventions to prevent LEA in patients with diabetes has previously been reported [17]. Our results suggest that, if intensified prevention can reduce the incidence of foot ulcers and amputations by $25 \%$, the simulated prevention strategy would be cost-effective or cost-saving in all patients with diabetes in Sweden except those without specific risk factors. 
This result seems reasonable because a relation between prevention and a decreased incidence of amputations has been described [2, 23-25, 39-41] as well as results indicating a lower risk of minor foot problems and foot ulcers after interventions with education, foot care or appropriate footwear [23-25, 42-51]. Although the studies indicating foot ulcer reductions are somewhat less conclusive it is nevertheless likely that the preventive strategies modeled in our study with a combination of the three strategies would have an influence on the occurrence of foot lesions. This is especially probable because the assumptions with $25 \%$ lower incidence of foot ulcers and amputations are more conservative than the results of prevention reported from most of the published reports.

The costs of patient education, foot care, and protective or treatment footwear are small, perhaps even negligible, when considered as single measures for one patient and especially in contrast to the high costs of foot ulcer treatment and amputations [14-16]. However, prevention must be provided for a large number of patients over many years, often for the remaining lifetime, thus the total costs of prevention will be high. Nevertheless, the additional costs of optimal prevention in our baseline model could be offset in seven of the nine age cohorts in the three most severe risk groups by reduced costs for treatment of foot ulcers and amputations. In addition, a further increase of the resources used for prevention as examined in the sensitivity analyses had no major effect on the results.

A model simulation is always associated with a degree of uncertainty. Our model was simplified in some ways that may have influenced the results. First, the model did not follow the total remaining lifetime of the patients, just five years because further mortality rates for patients with diabetes and different foot ulcer risk were not available. However, optimal prevention during the remaining lifetime of patients would probably not be less favourable than the baseline five-year prevention program. A variation of the discount rates had no impact of the major results.

Another factor that could influence the cost-effectiveness of preventive foot programmes is patient compliance [24]. To compensate for non-compliance and avoid biasing of the results, all patients in the present model simulations were assumed to receive optimal prevention in accordance with their risk profile but the effect on the development of foot ulcers and reduction of LEA was varied.

In our study, the foot ulcer and amputation risks were not age-specific because of data limitations, which might also have influenced the results. Previous reports have found an increasing incidence of LEA with higher age $[12,52,53]$, though another study reported no association between age and amputation risk [54]. A selection bias in the decision to per- form more major amputations on older than in younger patients could be a contributory cause to higher amputation incidences in older patients. In a study from Wisconsin, there was an increase in amputations with age in patients with Type I (insulin-dependent) diabetes mellitus, though no such association with age was found in Type II diabetic patients [55]. Results from a Swedish study showed a $78 \%$ decrease in the incidence of major amputations during 12 years [2]. The decrease was most marked in ages above 80 resulting in an almost equal incidence of major amputations in the 60 to 79 age groups and patients older than 80 years. Based on these results, the use of the same amputation risks for the three age groups in our model has probably not affected the results in a systematic way. Modifications of the model would be necessary in settings with large disparities in incidence rates of ulceration and LEA between different ages.

Patient characteristics such as age, sex, diabetes duration, insulin treatment, and Type I diabetes in the reference population corresponded fairly well with previously described population based studies of diabetic patients in Sweden [56, 57]. The reference population which provided background data for the study [18] could therefore be supposed to be representative for the Swedish population of patients with diabetes.

The present model seems appropriate for simulating the effects of prevention on long-term costs associated with foot ulcers and amputations. The model can be used for future cost-effectiveness and costutility analyses of diabetic foot ulcer prevention when new information about prevention and treatment costs, outcome results, and quality of life will be available.

In conclusion, an intensified prevention strategy including patient education, foot care and footwear, as simulated in our study, is cost-saving in all high risk patients with an assumption of $25 \%$ incidence reduction of both foot ulcers and LEA. Under the same set of assumptions, the prevention strategy would be cost-effective or cost-saving in all other patients with diabetes except in low risk patients without specific risk factors. To provide all diabetic patients at risk or at high risk for foot ulcers and amputations with the recommended prevention would be cost-effective.

Acknowledgements. This study was funded by an educational grant from the National Corporation of Swedish Pharmacies. 


\section{References}

1. Frykberg RG (1998) The team approach in diabetic foot management. Adv Wound Care 11: 71-77

2. Larsson J, Apelqvist J, Agardh C-D, Stenström A (1995) Decreasing incidence of major amputation in diabetic patients: a consequence of a multidisciplinary foot care team approach? Diabet Med 12: 770-776

3. American Diabetes Association (1999) Consensus development conference on diabetic foot wound care. Diabetes Care 22: 1354-1360

4. American Diabetes Association (2000) Preventive foot care in people with diabetes. Diabetes Care 23 [Suppl 1]:S55-S56

5. Spri (1998) Consensus statement. Foot problems of diabetics. Spri Publications, Stockholm, Report No.: 329

6. International Working group on the Diabetic Foot (1999) International consensus on the diabetic foot. The International Working Group on the Diabetic Foot, Amsterdam

7. NBHW, National Board of Health and Welfare (1994) Diabetesvården i Stockholms läns landsting. Kartläggning, utvärdering, kvalitetsmätning. Socialstyrelsens aktiva uppföljning. Stockholm: Socialstyrelsen, NBHW

8. NBHW (1992) Diabetesvård i Norrbotten och Västerbotten - struktur och kvalitet. Socialstyrelsens aktiva uppföljning. Stockholm: Socialstyrelsen, NBHW

9. Walrond ER, Ramesh J (1998) Quality of care of patients with diabetic foot problems in Barbados. West Indian Med J 47: 98-101

10. Pinzur MS (1999) American orthopaedic foot and ankle society diabetic shoe survey. Diabetes Care 22: 2099-2100

11. Mühlhauser I, Overmann H, Bender R, et al. (1998) Social status and the quality of care for adult people with Type I (insulin-dependent) diabetes mellitus - a population-based study. Diabetologia 41: 1139-1150

12. Reiber GE, Pecoraro RE, Koepsell TD (1992) Risk factors for amputation in patients with diabetes mellitus. A casecontrol study. Ann Intern Med 117: 97-105

13. Ollendorf DA, Kotsanos JG, Wishner WJ, et al. (1998) Potential economic benefits of lower-extremity amputation prevention strategies in diabetes. Diabetes Care 21: 1240-1245

14. Apelqvist J, Ragnarson Tennvall G, Persson U, Larsson J (1994) Diabetic foot ulcers in a multidisciplinary setting. An economic analysis of primary healing and healing with amputation. J Intern Med 235: 463-471

15. Apelqvist J, Ragnarson Tennvall G, Larsson J, Persson U (1995) Long-term costs for foot ulcers in diabetic patients in a multidisciplinary setting. Foot Ankle Int 16: 388-394

16. Holtzer SES, Camerota A, Martens L, Cuerdon T, CrystalPeters J, Zagari M (1998) Cost and duration of care for lower extremity ulcers in patients with diabetes. Clin Ther 20: 169-181

17. Klonoff DC, Schwartz DM (2000) An economic analysis of interventions for diabetes. Diabetes Care 23: 390-404

18. Hjelm K, Apelqvist J, Nyberg P, Sundquist J, Isaksson $\AA$ (1997) Health, health care utilization and living conditions in foreign-born diabetic patients in southern Sweden. J Intern Med 242: 131-141

19. Falkenberg M (1998) Vilka organisatoriska principer ger optimal prevention och behandling. Primärvårdens roll screening, prevention och utbildning. In: Diabetikers fotproblem. Konsensuskonferens 1998. Spri Publications, Stockholm, p. 114-122

20. Sonnenberg FA, Beck JR (1993) Markov models in medical decision making: a practical guide. Med Decis Making 13: $322-338$
21. Briggs A, Sculpher M (1998) An introduction to Markov modelling for economic evaluation. Pharmacoeconomics 13: 397-409

22. Apelqvist J, Ragnarson Tennvall G, Larsson J (1995) Topical treatment of diabetic foot ulcers: an economic analysis of treatment alternatives and strategies. Diabet Med 12: 123-128

23. Malone JM, Snyder M, Anderson G, Bernhard VM, Holloway GA, Bunt TJ (1989) Prevention of amputation by diabetic education. Am J Surg 158: 520-524

24. McCabe CJ, Stevenson RC, Dolan AM (1998) Evaluation of a diabetic foot screening and protection programme. Diabet Med 15: 80-84

25. Patout CA, Birke JA, Horswell R, Williams D, Cerise FP (2000) Effectiveness of a comprehensive diabetes lower-extremity amputation preventive program in a predominantly low-income African-American population. Diabetes Care 23: 1339-1342

26. Nelzén O (1997) Patients with chronic leg ulcer. Aspects on epidemiology, aetiology, clinical history, prognosis and choice of treatment [Thesis]. Uppsala University, Uppsala

27. Abbott CA, Vileikyte L, Williamson S, Carrington AL, Boulton AJM (1998) Multicenter study of the incidence of and predictive risk factors for diabetic neuropathic ulceration. Diabetes Care 21: 1071-1075

28. Apelqvist J, Larsson J, Agardh C-D (1993) Long-term prognosis for diabetic patients with foot ulcers. J Intern Med 233: 485-491

29. Ragnarson Tennvall G, Apelqvist J, Eneroth M (2000) Costs of deep foot infections in patients with diabetes mellitus. Pharmacoeconomics 18: 225-238

30. Apelqvist J, Larsson J, Agardh C-D (1992) Medical risk factors in diabetic patients with foot ulcers and severe peripheral vascular disease and their influence on outcome. J Diabetes Complications 6: 167-174

31. Jönsson B, Ragnarson Tennvall G (1998) Vilka är de samhällsekonomiska konsekvenserna av val av strategi för prevention och behandling? In: Diabetikers fotproblem. Konsensuskonferens 1998. Spri Publications, Stockholm. p. 148-161

32. Gold MR, Siegel JE, Russel LB, Weinstein MC (1996) Cost-effectiveness in health and medicine. Oxford University Press, New York, Oxford

33. Drummond MF, O'Brien B, Stoddard GL, Torrance GW (1997) Methods for the economic evaluation of health care programmes. $2^{\text {nd }}$ edn. Oxford Medical Publications, Oxford

34. Landstingsförbundet (2000) Statistisk årsbok för landsting 2000 (Statistical yearbook for county councils 2000). Landstingsförbundet (The Federation of County Councils), Stockholm

35. U.K. Prospective Diabetes Study Group (1999) Quality of life in type 2 diabetic patients is affected by complications but not by intensive policies to improve blood glucose or blood pressure control (UKPDS 37). Diabetes Care 22: 1125-1136

36. Ragnarson Tennvall G, Apelqvist J (2000) Health-related quality of life in patients with diabetes mellitus and foot ulcer. J Diabetes Complications 14: 235-241

37. Larsson J, Apelqvist J (1995) Towards less amputations in diabetic patients. Incidence, causes, cost, treatment, and prevention - a review. Acta Orthopod Scand 66: 181-192

38. Young MJ, Breddy JL, Veves A, Boulton AJM (1994) The prediction of diabetic neuropathic foot ulceration using vibration perception thresholds. A prospective study. Diabetes Care 17: 557-560 
39. Falkenberg M (1990) Metabolic control and amputations among diabetics in primary health care - a populationbased intensified programme governed by patient education. Scand J Prim Health Care 8: 25-29

40. Griffiths GD, Wieman TJ (1992) Meticulous attention to foot care improves the prognosis in diabetic ulceration of the foot. Surg Gynecol Obstet 174: 49-51

41. Sowell RD, Mangel WB, Kilczewski CJ, Normington JM (1999) Effect of podiatric medical care on rates of lowerextremity amputation in a Medicare population. J Am Podiatr Med Assoc 89: 312-317

42. Dargis V, Pantelejeva O, Jonushaite A, Vileikyte L, Boulton AJM (1999) Benefits of a multidisciplinary approach in the management of recurrent diabetic foot ulceration in Lithuania. Diabetes Care 22: 1428-1431

43. Edmonds ME, Blundell MP, Morris ME, Maelor Tomas E, Cotton LT, Watkins PJ (1986) Improved survival of the diabetic foot: the role of a specialised foot clinic. Q J Med 60: 763-771

44. Litzelman DK, Slemenda CW, Langefeld CD, et al. (1993) Reduction of lower extremity clinical abnormalities in patients with non-insulin-dependent diabetes mellitus. A randomized, controlled trial. Ann Intern Med 119: 36-41

45. Marciniak M (1998) Qualifizierte Fusspflege/Behandlung zur Rehabilitation von Patienten mit diabetischem FussSyndrom. Eine Kohortenstudie. Diab Stoffw 7: 81-85

46. Chantelau E, Haage P (1994) An audit of cushioned diabetic footwear: relation to patient compliance. Diabet Med 11: 114-116

47. Chantelau E, Kushner T, Spraul M (1990) How effective is cushioned therapeutic footwear in protecting diabetic feet? A clinical study. Diabet Med 7: 355-359

48. Uccioli L, Faglia E, Monticone G et al. (1995) Manufactured shoes in the prevention of diabetic foot ulcers. Diabetes Care 18: 1376-1378
49. Rönnemaa T, Hämäläinen $H$, Toikka $T$, Liukkonen I (1997) Evaluation of the impact of podiatrist care in the primary prevention of foot problems in diabetic subjects. Diabetes Care 20: 1833-1837

50. Pieber TR, Holler A, Siebenhofer A, et al. (1995) Evaluation of a structured teaching and treatment programme for type 2 diabetes in general practice in a rural area of Austria. Diabet Med 12: 349-354

51. Barth R, Campbell LV, Allen S, Jupp JJ, Chisholm DJ (1991) Intensive education improves knowledge, compliance, and foot problems in Type 2 diabetes. Diabet Med 8: $111-117$

52. van Houtum WH, Lavery LA (1996) Regional variation in the incidence of diabetes-related amputations in the Netherlands. Diabetes Res Clin Pract 31: 125-132

53. Bild DE, Selby JV, Sinnock P, Browner WS, Braveman P, Showstack JA (1989) Lower-extremity amputation in people with diabetes. Epidemiology and prevention. Diabetes Care 12: 24-31

54. Adler AI, Boyko EJ, Ahroni JH, Smith DG (1999) Lowerextremity amputation in diabetes. The independent effects of peripheral vascular disease, sensory neuropathy, and foot ulcers. Diabetes Care 22: 1029-1035

55. Moss SE, Klein R, Klein BEK (1992) The prevalence and incidence of lower extremity amputation in a diabetic population. Arch Intern Med 152: 610-616

56. Lundman B, Engström L (1998) Diabetes and it's complications in a Swedish county. Diabetes Res Clin Pract 39: 157-164

57. Wändell PE, Brorsson B, Åberg H (1997) Quality of life in diabetic patients registered with primary healthcare services in Sweden. Scand J Prim Health Care 15: 97-102 